\title{
TCR-dependent transformation of mature memory phenotype T cells in mice
}

\author{
Xi Wang, 1,2,3 Miriam B.F. Werneck, ${ }^{4,5}$ Boris G. Wilson,, ${ }^{1,2,3}$ Hye-Jung Kim,4,5 Michael J. Kluk, ${ }^{6}$ \\ Christopher S. Thom, 1,2,3 Jonathan W. Wischhusen,1,2,3 Julia A. Evans, 1,2,3 Jonathan L. Jesneck, 1,7 \\ Phuong Nguyen, ${ }^{1,2,3}$ Courtney G. Sansam, ${ }^{1,2,3}$ Harvey Cantor, ${ }^{4,5}$ and Charles W.M. Roberts ${ }^{1,2,3}$
}

\begin{abstract}
${ }^{1}$ Department of Pediatric Oncology, Dana-Farber Cancer Institute, Boston, Massachusetts, USA. 2Division of Hematology/Oncology, Children's Hospital Boston, Boston, Massachusetts, USA. ${ }^{3}$ Department of Pediatrics, Harvard Medical School, Boston, Massachusetts, USA. ${ }^{4}$ Department of Cancer Immunology and AIDS, Dana-Farber Cancer Institute, Boston, Massachusetts, USA. ${ }^{5}$ Department of Pathology, Harvard Medical School, and ${ }^{6}$ Department of Pathology, Brigham and Women's Hospital, Harvard Medical School, Boston, Massachusetts, USA. ${ }^{7}$ Cancer Program, Broad Institute of Harvard and Massachusetts Institute of Technology, Boston, Massachusetts, USA.
\end{abstract}

\begin{abstract}
A fundamental goal in cancer research is the identification of the cell types and signaling pathways capable of initiating and sustaining tumor growth, as this has the potential to reveal therapeutic targets. Stem and progenitor cells have been implicated in the genesis of select lymphoid malignancies. However, the identity of the cells in which mature lymphoid neoplasms are initiated remains unclear. Here, we investigate the origin of peripheral T cell lymphomas using mice in which Snf5, a chromatin remodelling-complex subunit with tumor suppressor activity, could be conditionally inactivated in developing $T$ cells. In this model of mature peripheral $T$ cell lymphomas, the cell of origin was a mature $C D 44^{\text {hi }} \mathrm{CD} 122^{10} \mathrm{CDB}^{+} \mathrm{T}$ cell that resembled a subset of memory cells that has capacity for self-renewal and robust expansion, features shared with stem cells. Further analysis showed that Snf5 loss led to activation of a Myc-driven signaling network and stem cell transcriptional program. Finally, lymphomagenesis and lymphoma proliferation depended upon TCR signaling, establishing what we believe to be a new paradigm for lymphoid malignancy growth. These findings suggest that the selfrenewal and robust proliferative capacities of memory $T$ cells are associated with vulnerability to oncogenic transformation. Our findings further suggest that agents that impinge upon TCR signaling may represent an effective therapeutic modality for this class of lethal human cancers.
\end{abstract}

\section{Introduction}

Little is known definitively about the cellular origins of cancer, as initiation occurs long before tumors become apparent. Consequently, the identity of the initiating cell is frequently speculative, based upon extrapolations from tumor cell phenotypes. However, since the selective pressure that occurs during oncogenic transformation is intense, nascent cancer cells can undergo substantial phenotypic evolution, making the validity of such extrapolations uncertain. One approach to investigate the potential origins of cancer has been to expose selected cell populations to exogenously expressed oncogenes. Such studies have shown that long-lived stem cells and early progenitor cells are capable of giving rise to cancers, although such data is not derived from spontaneously arising cancers in vivo $(1,2)$. Additional support for a stem cell origin of cancer has come from findings that stem cell-and self-renewal-associated programs are enriched in multiple tumor types $(1,3-7)$.

However, at least some cancers may arise from more differentiated cells. For instance, transduction of Ink4a/Arf/- astrocytes with constitutively active EGFR can induce a high-grade glioma phenotype (8). Additionally, ectopic expression of MLL-AF9 can drive transformation of both committed progenitors and cells expressing mature myeloid lineage-specific antigens $(1,9)$. Consequently, the intrinsic cellular features that confer the greatest susceptibility to transformation in vivo and the mechanisms that underlie the reprogramming are largely unclear.

Authorship note: Xi Wang and Miriam B.F. Werneck contributed equally to this work.

Conflict of interest: The authors have declared that no conflict of interest exists. Citation for this article: JClin Invest. 2011;121(10):3834-3845. doi:10.1172/JCI37210.
The SWI/SNF complex, also known as the BRG1-associated factor (BAF) complex, regulates chromatin structure and plays fundamental roles in the epigenetic regulation of gene expression and in the control of cell fate (10). Its activity has been implicated in the maintenance of embryonic stem cell pluripotency and in enhancing the formation of iPS cells $(11,12)$. Inactivating mutations in SWI/ SNF subunits are increasingly being identified at high frequency in a variety of human cancer types, including SWI/SNF-related, matrix-associated, actin-dependent regulator of chromatin, subfamily b, member 1 (SMARCB1, also known as SNF5) in rhabdoid tumors, Schwannomatosis, and a familial cancer predisposition syndrome; AT-rich interactive domain 1A (ARID1A, also known as BAF250A) mutations in ovarian and endometrioid carcinomas; SWI/SNF-related, matrix-associated, actin-dependent regulator of chromatin, subfamily a, member 4 (SMARCA4, also known as BRG1) in lung cancers; and most recently polybromo 1 (PBRM1, also known as BAF180) in renal carcinomas (10,13-18). In addition to homozygous inactivation, haploinsufficiency for SWI/SNF subunits has been implicated in a number of cancers as well. The SWI/SNF complex serves specific roles in lymphoid development and may also play a role in lymphoid malignances, as $50 \%$ of $\mathrm{T}$ cell prolymphocytic leukemias display deletions at 22q11, the location of SNF5 $(19,20)$. Also, inactivation of Snf5 in mice leads to rapid onset of mature peripheral $\mathrm{T}$ cell lymphomas (PTCLs) in all mice, with a median onset of only 11 weeks $(21,22)$. Consequently, mutation of the Swi/Snf complex is relevant to a variety of lethal human cancers, making its underlying biology of great interest.

Despite its roles in human cancer, the mechanisms underlying the tumor suppressor activity of the SWI/SNF complex, its role in lymphoid development, and the origin of these cancers are poorly 


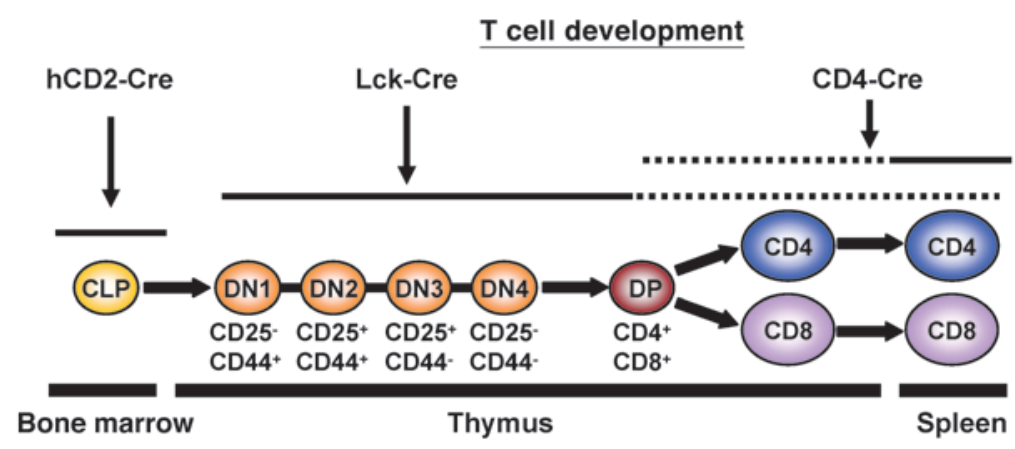

\section{Figure 1}

Schematic of T cell development. CLP cells originate in the bone marrow and migrate to the thymus. Cells at the CD4-CD8- DN stage are divided into 4 sequential subsets (DN1-DN4) according to expression of CD44 and CD25. Expression of the pre-TCR at DN3 leads to progression to DN4, followed by expression of CD4 and CD8 and progression to the CD4+CD8+ DP stage. Positive selection then leads to commitment toward the CD4 or the CD8 T cell lineage. Mature CD4 and CD8 single-positive cells then migrate to the periphery. The hCD2-Cre transgene is expressed at the CLP stage, leading to Snf5 deletion prior to arrival in the thymus. The Lck-Cre transgene is initially activated during early intrathymic development. The CD4-Cre transgene results in loss of Snf5 protein only in mature (CD4 and CD8) T cells in the periphery.

understood. The T cell compartment provides an ideal model with which to genetically pinpoint the origin of cancer and elucidate mechanisms in view of its well-characterized stepwise development from HSCs to lineages of mature T cells. In addition, unlike differentiated cells in other tissues, a subset of mature $\mathrm{T}$ cells, termed memory cells, can renew themselves and persist throughout the lifetime of an individual. This property is associated with expression of a transcriptional program associated with cellular self-renewal, similar to the program of long-term HSCs (23), a cell type that has been implicated in the initiation of cancer $(2,24,25)$. The susceptibility of HSCs to transformation has been linked to their intrinsic capacities for self-renewal and proliferation, leading to our hypothesis that memory $\mathrm{T}$ cells, in which self-renewal is uncoupled from the stem/progenitor stage of differentiation, may be similarly susceptible to malignant transformation.

Lastly, although postulated over 25 years ago (26), the contribution of TCR signaling to the initiation and expansion of T cell lymphomas has been difficult to define and has remained speculative. Such a role would be of great interest, both because of mechanistic insight and because of the therapeutic implications. The challenge in evaluating this arises in part because immune restriction precludes such questions from being directly tested using xenotransplantation. Thus primary animal models of mature $\mathrm{T}$ cell lymphoma are needed, which have been lacking.

Here, we have generated a staged series of genetically engineered in vivo models in order to identify the population of cells capable of giving rise to spontaneous lymphomas that possess phenotypic markers of mature cells, to characterize the underlying mechanisms, and to evaluate the role of TCR signaling in this process.

\section{Results}

Deletion of Snf5 at a late stage in T cell development results in lymphomagenesis. Inactivation of Snf5 in mice using an inducible Mx-Cre transgene results in the rapid formation of mature $\mathrm{CD} 3^{+} \mathrm{CD} 8^{+} \mathrm{CD} 4$ PTCLs and sarcomas with $100 \%$ penetrance and a median onset of 11 weeks (22). To initiate investigation of the mechanism of lymphomagenesis, we crossed Snf5-conditional mice to a series of deleter strains that act at different stages during $\mathrm{T}$ cell developmental progression. The hCD2-Cre transgene is expressed within the earli- est stem/progenitor stages of T cell development, becoming active at the common lymphoid progenitor (CLP) stage that gives rise to the $\mathrm{B}, \mathrm{T}$, and NK cell lineages; the Lck-Cre transgene is expressed during early intrathymic development as nascent $\mathrm{T}$ cells arrive in the thymus; and the CD4-Cre transgene is not expressed until late in thymic development, at the $\mathrm{CD}^{+} \mathrm{CD}^{+}$double-positive (DP) stage (Figure 1). Consistent with the early expression of hCD2Cre, thymocyte precursors in hCD2-Cre floxed Snf5 mice (hCD2Cre $S n f 5^{f l / f l}$ mice) already harbored deleted $S n f 5$ genes upon their arrival in the thymus at the $\mathrm{CD}^{-} \mathrm{CD}^{-}$- double-negative 1 (DN1) stage (Supplemental Figure 1A; supplemental material available online with this article; doi:10.1172/JCI37210DS1). This resulted in a $90 \%$ reduction in thymocyte numbers, reflecting a block at the DN3 stage of development (Figure 2A).

Snf5 deletion driven by the Lck-Cre transgene occurred somewhat later and was nearly complete by the DN4 stage (Supplemental Figure 1A). Similar to the effect seen in hCD2-Cre mice, thymocyte development in Lck-Cre animals was blocked at the DN3 stage (Figure 2A). However, consistent with the known incomplete penetrance of Lck-Cre expression (27), a small subpopulation ( $<10 \%)$ of thymocytes did not delete Snf5 until after the DN3 stage. Consequently, some cells proceeded past the DN3 stage and gave rise to mature Snf5-deficient peripheral T cells in Lck-Cre Snf5flfl mice, a situation that did not occur in hCD2-Cre mice (Figure 2B).

In contrast to those of hCD2-Cre and Lck-Cre, the developmental effects caused by the CD4-Cre transgene differed substantially. This transgene reproducibly led to a loss of Snf5 protein within mature $\mathrm{T}$ lymphocytes but not earlier. Although CD4 is expressed by DP thymocytes, due to the relatively long half-life of the Snf5 protein, loss of Snf5 was not complete until mature T cells reached the periphery (Supplemental Figure 1B). As a result, CD4-Cre Snf5 $5^{f l f l}$ mice, unlike the CD2-Cre and Lck-Cre mice, possessed normal thymocyte numbers and developmental thymocyte profiles (Figure 2A).

To determine whether the Snf5-deficient lymphomas were initiated by stem/progenitor cells and later acquired a mature phenotype or whether they arose from mature cells, we aged cohorts of mice from each of the Cre-transgene expressing lines. Mice from the hCD2-Cre $\operatorname{Snf} 5^{f / / f l}$ line aged normally and were not cancer prone. In contrast, all mice from both the Lck-Cre $\operatorname{Snf} 5^{f / f l}$ and CD4-Cre $\operatorname{Snf} 5^{f / / f l}$ 
A
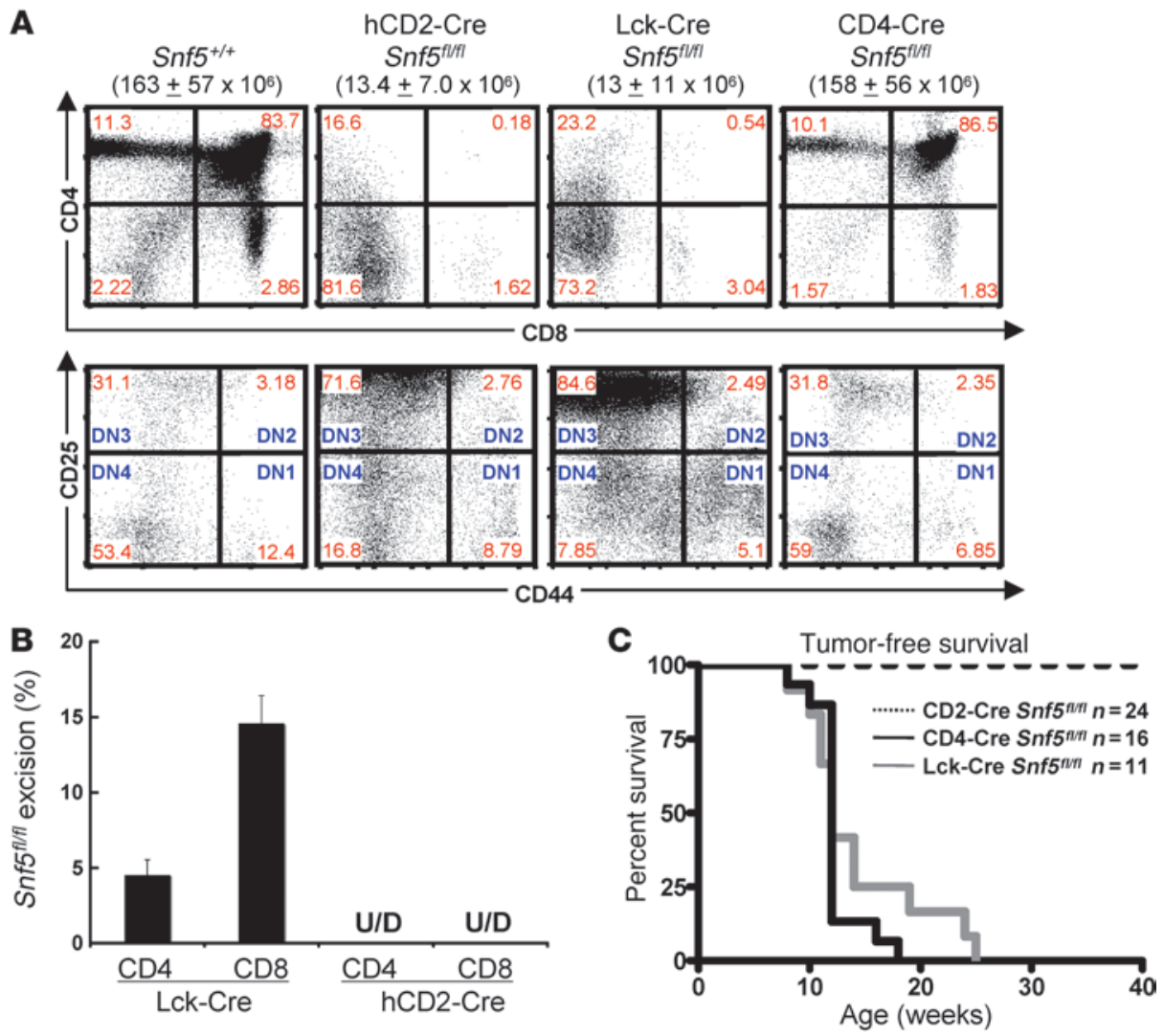

Figure 2

Deletion of Snf5 in T cells results in mature T cell lymphoma. (A) Flow cytometric analysis of thymocytes from WT (CD2-Cre Snf5+/+), Lck-Cre Snf5 f//fl, hCD2-Cre Snf5 fl/tl, and CD4-Cre Snf5 ${ }^{f / / f l}$ mice. The numbers above the plots indicate the total numbers of thymocytes averaged from 9 WT mice, 6 Lck-Cre Snfffl/fl mice, 9 hCD2-Cre Snf5 fl/fl mice, and 6 CD4-Cre Snf5fl/fl mice. The top row shows CD4 versus CD8 staining for all thymocytes. The bottom row is gated to show only the CD4-CD8DN population, and CD25 versus CD44 staining is used to resolve the DN1, DN2, DN3, and DN4 populations, as labeled in blue. The percentage of cells within each quadrant is labeled in red. (B) $\mathrm{CD}^{+}{ }^{+} \mathrm{CD} 4^{+}$or $\mathrm{CD}^{+}{ }^{+} \mathrm{CD} 8^{+} \mathrm{T}$ cells were sorted from the spleens of Lck-Cre Snf5 fl/fl mice $(n=8)$ or hCD2-Cre Snf5 $5^{f / f l}$ mice $(n=12)$, and deletion of the Snf5 allele was quantified by quantitative realtime PCR. Due to known variable penetrance of Lck-Cre expression, some T cells in Lck-Cre Snf5flftl mice do not undergo deletion until later stages of development. Consequently, the Lck-Cre Snf5f/fll mice contain a population of mature peripheral T cells that are Snf5 deficient, a key distinction from the hCD2-Cre Snf5 ${ }^{f / / f l}$ mice in which the deleted allele was undetectable (U/D) in peripheral T cells. (C) Tumor-free survival curve of hCD2-Cre Snf5t/flt mice $(n=24)$, Lck-Cre Snf5 $5^{f l / f l}$ mice $(n=11)$, and CD4-Cre Snf5 ${ }^{f / f I}(n=16)$ mice.

lines rapidly developed monoclonal/oligoclonal $\mathrm{TdT}^{-}, \mathrm{TCR}^{+}, \mathrm{CD}^{+}$, $\mathrm{CD}^{+}$, and CD4- mature PTCLs (Figure 2C and Supplemental Figures 2 and 3 ) located exclusively in spleen, liver, and occasionally lymph nodes but never thymus. Consequently, loss of Snf5 from mature $\mathrm{T}$ cells (CD4-Cre) but not early stem/progenitors (hCD2Cre) resulted in lymphoma development.

$C D 8^{+} C D 44^{h i} C D 122^{l o}$ subpopulation of $T$ cells is enriched in the absence of Snf5 and propagates lymphomas in vivo. In order to gain insight into the pathways and mechanisms driving oncogenesis, we next characterized the effect of Snf5 loss on T cell populations. We used a floxed GFP reporter transgene to identify individual cells that express Cre (Supplemental Figure 4). Analysis of $\mathrm{GFP}^{+} \mathrm{CD}^{+} \mathrm{T}$ cells in 3- to 4week-old Lck-Cre Snf $5^{f / l} / \mathrm{l}$ mice and in CD4-Cre Snf $5^{\ell / / f l}$ mice (weeks before overt lymphoma development) revealed a predominant phe- notype of $\mathrm{CD} 44^{\text {hi }} \mathrm{CD} 122^{\text {lo }} \mathrm{CD} 8$ cells (Figure 3A). High expression of CD44 on $\mathrm{CD}^{+} \mathrm{T}$ cells is a marker of memory phenotype (MP). Based on expression of the cell surface markers CD44 and CD122, mature $\mathrm{CD}^{+} \mathrm{T}$ cells can be divided into 3 subsets: $\mathrm{CD} 44^{\text {lo }} \mathrm{CD} 122^{\text {lo }}$ (naive), CD44hiCD122 $2^{\text {hi }}$ classical MP, and $\mathrm{CD} 44^{\mathrm{hi}} \mathrm{CD} 122^{\mathrm{lo}} \mathrm{MP}$ cells (28). The $\mathrm{T}$ cells in the Lck-Cre Snf5/flf mice and CD4-Cre Snf5 $5^{f / / l}$ mice had a surface phenotype consistent with that of the CD44hi CD122 $2^{\text {lo }}$ IL-15-independent subset of MP CD8 ${ }^{+} \mathrm{T}$ cells.

We next examined the Snf5-deficient lymphoma cells. A subpopulation of lymphoma cells (15\% of total) expressed the CD44hi phenotype, and a similar subpopulation of CD44hi cells was noted in a cell line that we generated from a Snf5-deficient lymphoma (Figure 3, B and C). Since expression of CD44 is a marker of the self-renewing, tumor-propagating subpopulation in solid tumors of several tissue types $(2,29)$, we hypothesized that CD44hi MP cells were responsible for sustaining the lymphoma. To test this hypothesis, we sorted the Snf5-deficient cell line into CD44hi and CD44to fractions before incubation for 40 days in culture, followed by repeat analysis of CD44 expression. The phenotype of the CD44lo fraction was stable: all cells remained $\mathrm{CD} 44^{\mathrm{lo}}$ after extended time in culture. In contrast, cells from the CD $44^{\text {hi }}$ fraction gave rise to both CD $44^{\text {hi }}$ and CD44 progeny (Figure 3D), thus recapitulating the parental lymphoma phenotype, consistent with the hypothesis that CD44hi cells can self-renew and give rise to $\mathrm{CD} 44^{\text {lo }}$ progeny.

As a more direct test of this hypothesis, we injected graded numbers of purified $\mathrm{CD} 44^{\mathrm{hi}}$ and $\mathrm{CD} 44^{\mathrm{lo}} \mathrm{lym}$ phoma cells into recipient mice. None of the mice injected with $10^{4} \mathrm{CD} 44^{\text {lo }}$ cells developed lymphoma, while all recipients of either $10^{4}$ or $10^{3} \mathrm{CD} 44^{\mathrm{hi}}$ and $75 \%$ of mice injected with as few as $10^{2} \mathrm{CD} 44^{\text {hi }}$ cells developed tumors (Table 1 and Figure 3E). The heterogeneous expression patterns of CD44 in the secondary tumors resembled the phenotypic complexity of the lymphoma cells from which they were derived. These secondary tumors contained both $\mathrm{CD} 44^{\mathrm{hi}} \mathrm{CD} 122^{\mathrm{lo}}$ and $\mathrm{CD} 44^{\mathrm{lo}} \mathrm{CD} 122^{\mathrm{lo}}$ populations (Figure 3F). Together, these in vitro and in vivo observations indicate that $\mathrm{CD} 8^{+} \mathrm{CD} 44^{\mathrm{hi}} \mathrm{CD} 122^{\mathrm{lo}}$ cells are the tumorpropagating cells.

We next evaluated whether lymphoma formation was dependent upon intrinsic properties of MP cells. To determine whether additional surface markers expressed by CD $44^{\text {hi }} \mathrm{CD} 122^{\text {lo }}$ Snf5-deficient lymphoma cells were consistent with the surface phenotype 
A
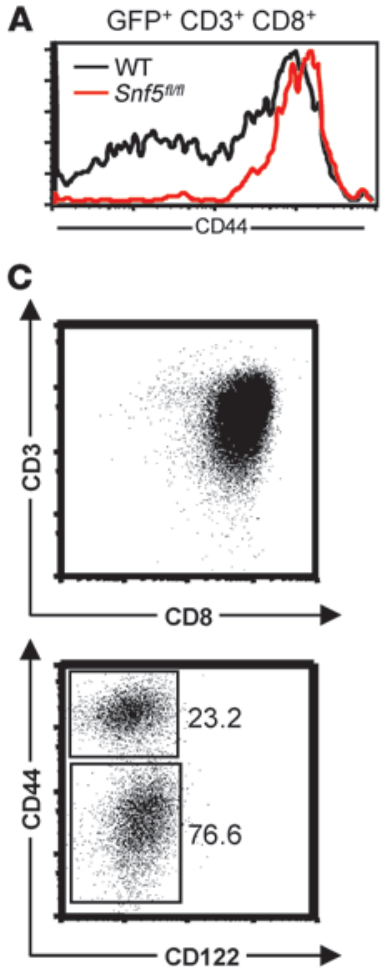

E

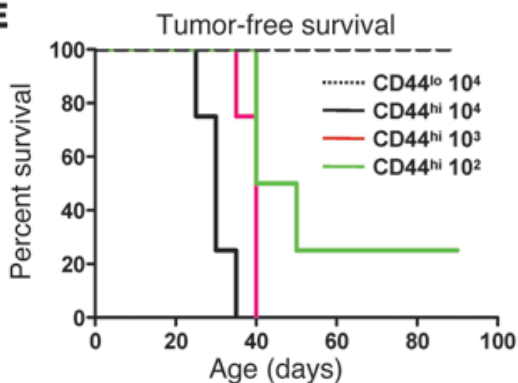

$\mathrm{GFP}^{+} \mathrm{CD}^{+} \mathrm{CD}^{+}$

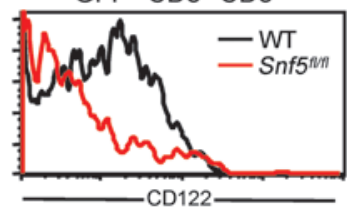

D
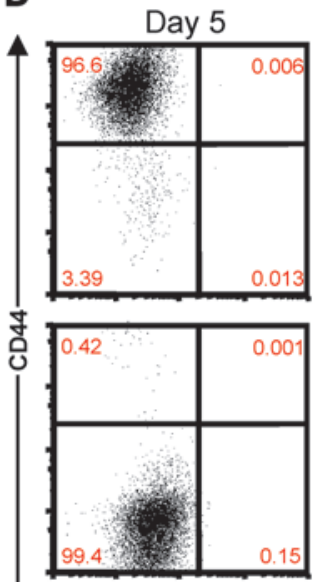

B

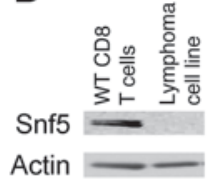

Day 15
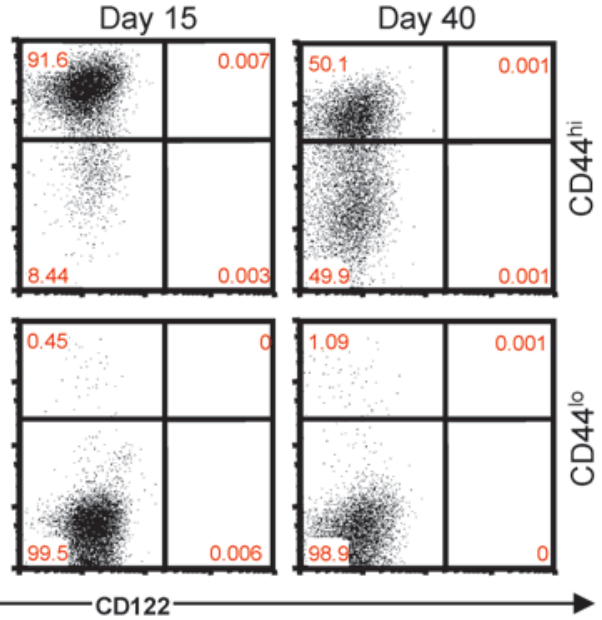

$\mathbf{F}$

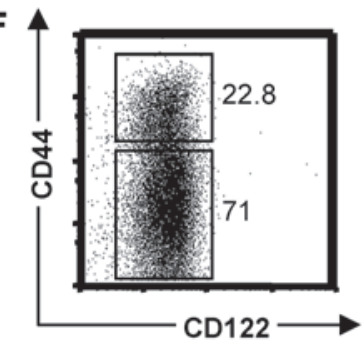

Figure 3

CD44hiCD122lo cells are the tumor-propagating cells. (A) CD3 ${ }^{+} C D 8^{+}$splenocytes from 4-week-old Lck-Cre GFP Snf5 WT (black lines) or Lck-Cre GFP Snf5//fl mice (red lines) were isolated, stained with antibodies for CD122 and CD44, and analyzed by FACS. Representative plots are shown. (B) Immunoblot of Snf5 expression in WT CD8 T cells and a lymphoma cell line. (C) Cells from the Snf5-deficient lymphoma cell line uniformly

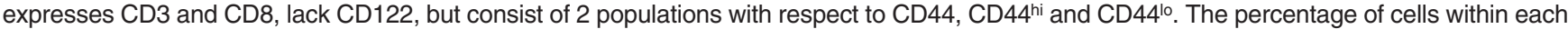
gate is indicated. (D) Snf5-deficient lymphoma cells were double sorted into CD44hi and CD44lo populations and then maintained in culture. CD44 and CD122 staining is shown from cells 5, 15, and 40 days after sorting. Only the CD44hi cells were capable of recapitulating the parent cell line phenotype by giving rise to both the CD44hi and the CD44/o populations. The percentage of cells within each quadrant is indicated. (E) Survival curve of mice injected with specified number of CD44hi or CD44lo cells derived from Snf5-deficient lymphomas. Each group contains 4 mice. (F) Flow cytometry analysis of tumors arising from recipient mice injected with $100 \mathrm{CD} 44^{\mathrm{hi}}$ cells. The percentage of cells within each gate is indicated.

of CD44hi CD122 ${ }^{\text {lo }}$ MP cells, we examined expression of CD25, CD62L, CD69, and CD127. In each case, we found the expression pattern was consistent with that of the $\mathrm{CD} 44^{\text {hi }} \mathrm{CD} 122^{\text {lo }} \mathrm{MP}$ population (ref. 28 and Supplemental Figure 5A). Moreover, like CD44hi $\mathrm{CD} 122^{\text {lo }} \mathrm{MP}$ cells and unlike naive cells and other MP populations, proliferation of Snf5-deficient lymphomas in culture was not enhanced by addition of recombinant IL-15 (Supplemental Figure 5B), and these tumor cells grew in IL-15-deficient recipients with the same kinetics as in WT hosts (Supplemental Figure $5 \mathrm{C}$ ). We then performed array-based gene expression analysis of the purified progenitor fraction from the Snf5-deficient lym- phoma cell line. We first compared the genome-wide expression signature of the Snf5-deficient lymphoma cells to a published data set containing both naive and memory expression signatures (23). The analysis revealed that the gene expression program in the CD44hi subset of lymphoma cells is distinct from that of naive $\mathrm{T}$ cells but highly similar to that of memory $\mathrm{T}$ cells (Figure 4A). In contrast, the gene expression signature of the CD $44^{\text {lo }}$ subpopulation is distinct from that of both naive and memory cells. Next, we performed gene set enrichment analysis (GSEA) (30), using a set of genes specifically expressed in memory cells, and also found significant enrichment of this set within the CD $44^{\text {hi }} \mathrm{CD} 122^{\text {lo }}$ lymphoma 


\begin{tabular}{|c|c|c|}
\hline \multirow[t]{2}{*}{$\begin{array}{l}\text { No. of cells } \\
\text { injected }\end{array}$} & \multicolumn{2}{|c|}{$\begin{array}{l}\text { Resultant no. of tumors } \\
\text { in recipients/total recipients }\end{array}$} \\
\hline & CD44 & CD44 $4^{10}$ \\
\hline $10^{4}$ & $4 / 4$ & $0 / 4$ \\
\hline $10^{3}$ & $4 / 4$ & $0 / 4$ \\
\hline $10^{2}$ & $3 / 4$ & $0 / 4$ \\
\hline $10^{1}$ & $0 / 4$ & $0 / 4$ \\
\hline
\end{tabular}

The CD $44^{\text {hi }}$ and $\mathrm{CD} 44^{\mathrm{l}}$ cells were isolated by flow cytometry, yielding a purity of $99.8 \%$ for CD $44^{\text {hi }}$ and $100 \%$ for CD $44^{\circ}$ cells. The indicated number of cells of each phenotype was intravenously injected into the tails of Rag2-/- recipient mice. The mice were observed daily for 6 months or until they became sick from lymphomas.

cell population $(P<0.0001)$ (Figure 4B). Finally, we specifically evaluated the expression of RANTES, a hallmark gene expressed in memory cells but not naive cells $(31,32)$, and found that it was highly expressed in the CD $44^{\text {hi }} \mathrm{CD} 122^{\text {lo }}$ subset (Figure 4C).

To address the hypothesis that lymphomas arose from CD44hi $\mathrm{CD} 122^{\text {lo }} \mathrm{MP}$ cells, we asked whether there was a correlation between enrichment of this population and the tumor-promoting activity of Snf5 loss. Brg1 is a core ATPase subunit of the Swi/Snf complex and, like SNF5, is mutated in a subset of human malignant rhabdoid tumors (10). Inactivation of Brg1 results in alterations in $\mathrm{T}$ cell development that are nearly indistinguishable from those of Snf5 loss $(33,34)$ but never results in lymphoma formation, regardless of the promoter driving Cre expression (Mx-Cre, Lck-Cre, or CD4-Cre) $(21,33)$. We evaluated peripheral T cells in CD4-Cre $B r g 1^{f / f l}$ mice by immunofluorescence and found that, unlike Snf5 loss, Brg1 loss does not lead to enrichment of CD44hi MP cells (Supplemental Figure 6), indicating a strong correlation between enrichment of MP cells in the absence of Snf5 and tumorigenesis.

Myc and stem cell-associated programs are aberrantly activated in Snf5deficient lymphomas. These findings suggest that Snf5 loss preferentially promotes survival of MP cells and expression of a MP gene expression program within lymphoma cells. We next sought to investigate the mechanism by which Snf5 loss drives transformation of this population. We recently demonstrated that Snf5 loss leads to upregulation of stem cell-associated programs (35). It has been reported that the similarities between gene expression programs in ES cells and cancers are due in large part to the pervasive activation of a Myc regulatory network rather than to a conserved stem cell program per se (36). We therefore evaluated expression of the Myc regulatory network as well as the newly identified ES cell core module, which is more specific for ES cell identity. The Myc module is composed of genes that are common targets of $7 \mathrm{Myc}$ network factors (Myc, Max, nMyc, Dmap1, E2F1, E2F4, and Zfx) (36), while the stem cell core module is composed of genes co-occupied by at least 7 factors among 9 ES core factors (Smad1, Stat3, Klf4, Oct4, Nanog, Sox2, Nac1, Zfp281, and Dax1) (36). We found that both the Myc module and the stem cell core module were enriched in lymphoma cells compared with WT T cells (Figure 5A). Western blot and GSEA further confirmed the upregulation of Myc itself and activation of an independently identified larger group of Myc targets (Figure 5, B-D). Notably, while these signatures were differentially expressed in the bulk Snf5-deficient lymphoma population compared with those in WT T cells, they were similarly activated in both CD44hi and CD44 ${ }^{\text {lo }}$ populations (data not shown). Consequently, the signatures reflected the effects of Snf5 loss but did not underlie the differential capacity of CD44hi and CD44lo cells to propagate or give rise to the bulk of the tumor. To determine whether these signatures were driven by Snf5 loss or were rather a general consequence of oncogenic transformation, we evaluated the signatures after Snf5 inactivation in non-transformed primary fibroblast cells. Importantly, in contrast to the lymphoma cells, Snf5 inactivation in primary fibroblasts results in cell cycle arrest (37). Nonetheless, the Myc and ESC-like modules were both enriched upon Snf5 loss (Figure 5, E and F), indicating that these changes were caused by Snf5 loss and not simply due to increased proliferation or transformation. Lastly, we asked whether these signatures were similarly enriched in human SNF5-deficient malignant rhabdoid tumors and found this to be the case (Figure 5G).

Initiation and maintenance of Snf5-deficient lymphomas depends on TCR expression. While TCR engagement may be dispensable for the survival of some MP subsets, the $\mathrm{CD} 8^{+} \mathrm{CD} 44^{\text {hi }} \mathrm{CD} 122^{\text {lo }}$ subpopulation is dependent upon TCR signaling for survival and expansion (28). Although oncogenic transformation results in acquisition of unlimited proliferation and diminished dependence upon growth factors, cancer cells can retain residual dependence upon pathways that normally control proliferation within the lineage of origin, such as breast cancer dependence upon estrogen and prostate cancer dependence upon androgen. We thus investigated the dependence of the lymphoma cells upon TCR engagement and signaling. Of note, the $\mathrm{CD} 3$ receptor complex is highly expressed on the lymphoma cells (Supplemental Figure 7A). Activation of TCR signaling results in the activation of NFAT1 through calcineurin-mediated dephosphorylation $(38,39)$, which can then activate Bclx, rendering cells resistant to apoptosis. Western blotting revealed that NFAT1 was activated in Snf5-deficient lymphoma cells (Supplemental Figure 7B), and both microarray and RT-PCR experiments revealed upregulation of NF- $\kappa \mathrm{B}$ and Bclx in these cells (Supplemental Figure $7, \mathrm{C}$ and D), consistent with active TCR signaling.

We next evaluated whether the failure to provoke lymphomas when Snf5 is deleted in immature thymocytes by hCD2-Cre could be due to a lack of TCR signaling and whether it could thus be remedied by provision of a mature TCR transgene. We chose the OT1 $\alpha \beta$ TCR to evaluate the role of MHC class I-restricted TCR signaling and introduced it into hCD2-Cre $\operatorname{Snf} f^{f / f f l}$ mice, which otherwise have a DN3 block and fail to develop lymphomas. The presence of the transgene resulted in presence of $\mathrm{Snf5}^{-1-}$ mature $\mathrm{T}$ cells in the periphery (Figure 6A), and all mice developed $\mathrm{CD}^{+} \mathrm{CD}^{+} \mathrm{T}$ cell lymphomas (Figure 6B), indicating that the addition of TCR transgene was sufficient to drive lymphoma formation in this model. To ask the reciprocal question, we evaluated whether elimination of TCR expression would block oncogenesis. We therefore crossed the Lck-Cre Snf5fl/fl mice onto a Rag2-/- background. The Lck-

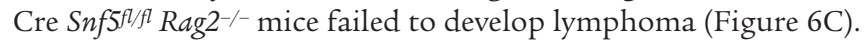
Together, these findings indicate that TCR expression is essential for tumor initiation in Snf5 mutant mice.

That TCR expression is essential for transformation led us to ask whether TCR-MHC interaction was essential for lymphoma maintenance and proliferation. We began by evaluating the effects of CD8 coreceptor blockade upon cultured lymphoma cells. Incubation of lymphoma cells in the presence of APCs led to robust proliferation (Figure 7A). Blockade of the CD8 TCR coreceptor by anti-CD8 antibody inhibited the proliferative response of lym- 
A

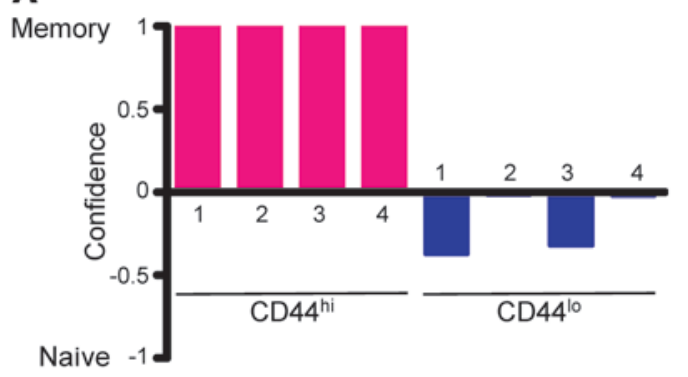

C
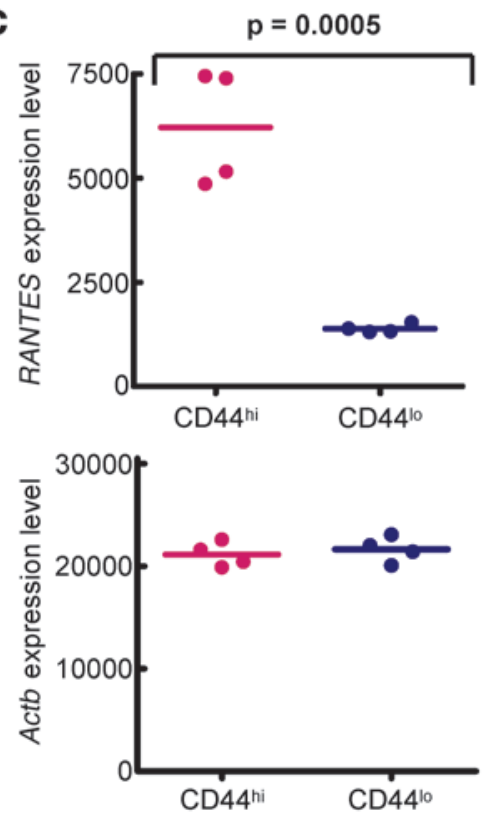

B CD44hi CD44to

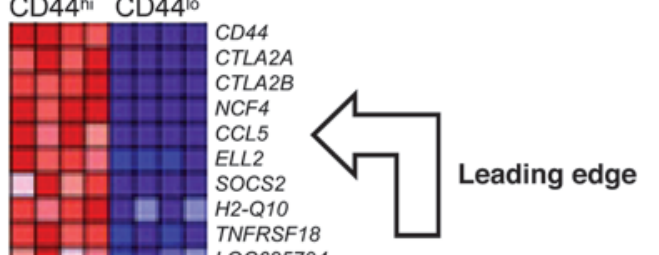

TNFRSF18

EOC625794 Enrichment plot: Genes highly expressed in memory cells STARD10 MAP $3 K 8$ IL 1ORA DAPK2 CXCR3 PCGF2 NRP1 IFNG BC004022 LGALS3 ID2 ID2 RHOQ
AA407659 AA4076
AIM1 MGST3 SMYD1 VCL $V C L$ HIP1R
SERPINB SERPIN
SOS2 MAPK12

GABARAPL2

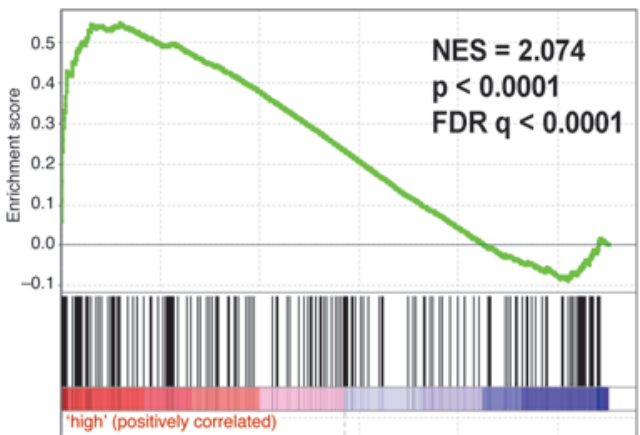

Figure 4

The CD44 hi subset of Snf5-deficient lymphoma cells has memory-like features. (A) Evaluation of global gene expression using KNN analysis. The signatures of $\mathrm{CD} 44^{\mathrm{hi}}$ and $\mathrm{CD} 44^{\mathrm{lo}}$ subsets from 4 independent Snf5-deficient lymphomas were compared with previously published gene signatures for naive and memory cell populations. Enrichment for the memory signature is indicated by an upward positive deflection of the bars, while enrichment for the naive signature is indicated by a downward negative deflection. (B) GSEA of a set of genes highly expressed in memory cells. Upward deflection of the green line indicates enrichment of the memory signature within the CD44hi population $(P<0.0001)$. FDR, false discovery rate; NES, normalized enrichment score. (C) Relative expression of RANTES (top) and Actb (bottom) by sorted CD44hi and CD44lo Snf5-I- lymphoma subpopulations determined by array-based gene expression analysis. Horizontal bars indicate the mean.

phoma cells (Figure 7B). Since this pathway depends on activation of calcineurin and can be inhibited by cyclosporin A (CsA) (40), we asked whether CsA treatment would affect lymphoma cell growth. CsA inhibited proliferation of Snf5-deficient lymphoma cells (Figure $7 \mathrm{C}$ ), and combined addition of CsA and anti-CD8 antibody to lymphoma cultures exerted a synergistic inhibitory effect (Figure 7D). Importantly, TCR signaling was essential for proliferation of the Snf5-deficient lymphoma cells and was not simply serving a $T$ cell survival function, as the reduction in thymidine incorporation caused by TCR blockade occurred without an increase in cell death (Supplemental Figure 8).

Lastly, in order to more definitively test the dependence of Snf5deficient lymphomas upon TCR signaling, we evaluated the role of engagement of the TCR by MHC/peptide ligand on lymphoma growth in vivo. Lymphoma cells from Lck-Cre Snf5flfl mice were transferred into MHC class I-deficient $K^{b-/-} D^{b-/-}$ C57BL/6 (41) or control C57BL/ 6 hosts. Although NK lysis by MHC-deficient host cells would not be expected to diminish lymphoma growth, recipients were irradiated (4 Gy) to prevent potential NK effects. We found that lymphomas developed in all control C57BL/6 recipients but in none of the MHC class I-deficient $K^{b-1-} D^{b-/-}$ hosts (Figure 7E), indicating that TCR engagement by MHC class I molecules is essential for lymphoma cell proliferation.

Downregulation of SNF5 in buman PTCLs. Since Snf5 deletion in murine T cells leads to tumorigenesis in mature $T$ cells, we asked whether SNF5 may play a role in the genesis of human PTCLs as well. Malignancies in T cells can be classified into 2 major categories: precursor $\mathrm{T}$ cell lymphoblastic neoplasms, which express markers consistent with maturing thymocytes, and PTCLs, which express markers consistent with mature post-thymic T cells. We used published gene expression data from human $\mathrm{T}$ cell cancers (42) to evaluate the levels of SNF5 expression. In normal 
A

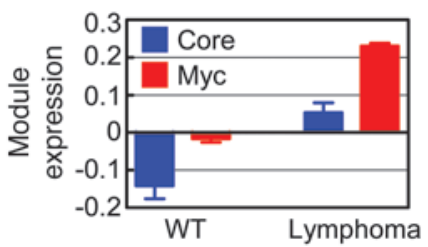

C Data set: lymphoma vs. $\mathrm{CD}^{+} \mathrm{T}$ cells Enrichment plot: Myc module

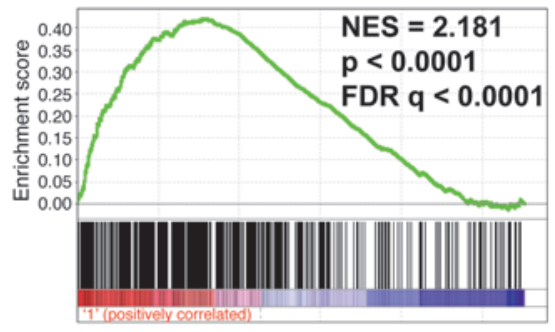

$\mathbf{E}$

Data set: Snf5-- MEFs vs. WT MEFs Enrichment plot: Myc module

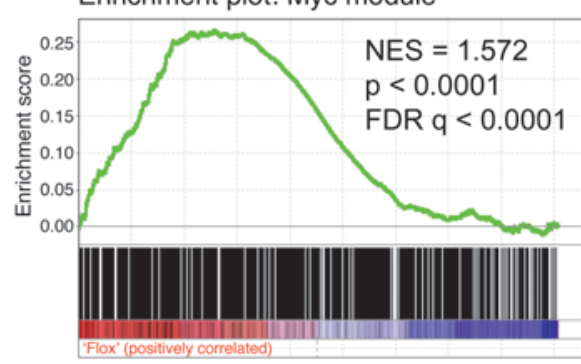

B

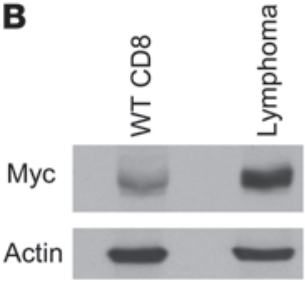

D Data set: lymphoma vs. CD8+ $\mathrm{T}$ cells Enrichment plot: Myc target genes

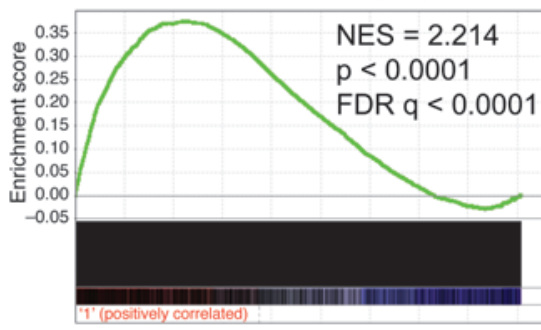

F

F Data set: Snf5-- MEFs vs. WT MEFs Enrichment plot: Myc target genes

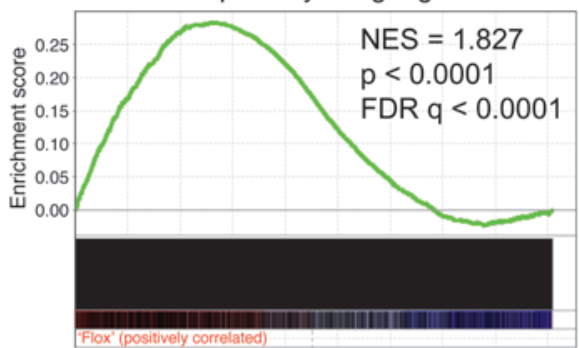

\section{Figure 5}

Snf5 loss leads to activation of Myc module. (A) Average gene expression values $\left(\log _{2}\right)$ of core stem cell modules and Myc regulatory network are tested in WT CD8+ T cells and Snf5-deficient CD8+ lymphoma cells. (B) Myc protein levels are elevated in Snf5-deficient Iymphomas. Immunoblot analysis of Myc in WT CD8+ $T$ cells and Snf5deficient CD8+ lymphoma cells. (C-G) GSEA of defined (C, E, and $\mathbf{G}$ ) Myc module or ( $\mathbf{D}$ and $\mathbf{F}$ ) Myc target genes in expression data from $(\mathbf{C}$ and $\mathbf{D})$ purified Snf5-deficient CD8+ lymphoma cells compared with WT CD8 ${ }^{+}$T cells, ( $E$ and $F$ ) Snf5-deficient MEFs compared with WT MEFs, and $(\mathbf{G})$ human SNF5-deficient malignant rhabdoid tumor (MRT) samples compared with normal cerebellum.

G Data set: Snf5 $5^{-1-}$ human MRT vs. cerebellum Enrichment plot: Myc target genes

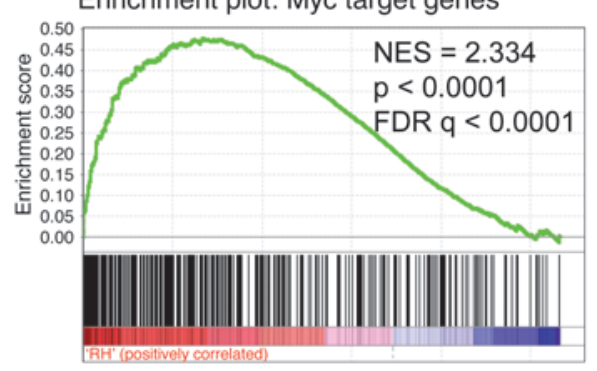

tissues, SNF5 is ubiquitously expressed. Using this data set, we found that SNF5 is expressed both in normal T cells as well as in immature lymphoblastic $\mathrm{T}$ cell leukemias and lymphomas (Figure 8). However, we found that SNF5 is expressed at reduced to undetectable levels in $40 \%$ of PTCLs (Figure 8). To exclude the possibility that peripheral $\mathrm{T}$ cells intrinsically have substantial variation with respect to SNF5 expression level, we performed immunohistochemical staining of SNF5 in normal spleen, lymph node, and thymus from both humans and mice. We observed that $\mathrm{T}$ cells and thymocytes expressed SNF5 and that the staining intensity did not vary substantially (Supplemental Figures 9 and 10). Consequently, the reduced levels of SNF5 in PTCLs compared with those in normal $\mathrm{T}$ cells and in lymphoblastic malignant cells raised the possibility of a causative link between downregulation/ inactivation of SNF5 and the genesis of human PTCLs.

\section{Discussion}

Transformation of mature $T$ cells. Identification of the cells from which cancers originate has been an area of intense interest, albeit difficult to study. Although many tumors may well arise from relatively undifferentiated cells, some lethal cancers express features of differentiated mature cells. Perhaps the most suggestive examples are from human PTCLs that express monoclonal TCR or Ig rearrangements and express surface markers characteristic of mature T or B cells (43-45). However, it is difficult to establish the cell of origin of these cancers in humans, because tumor initiation occurs long before patients come to clinical attention. Moreover, characterization of the tumor-propagating cells and evaluation of TCR signaling using xenotransplantation is difficult as these lymphomas are largely dependent upon the human microenvironment and do not 

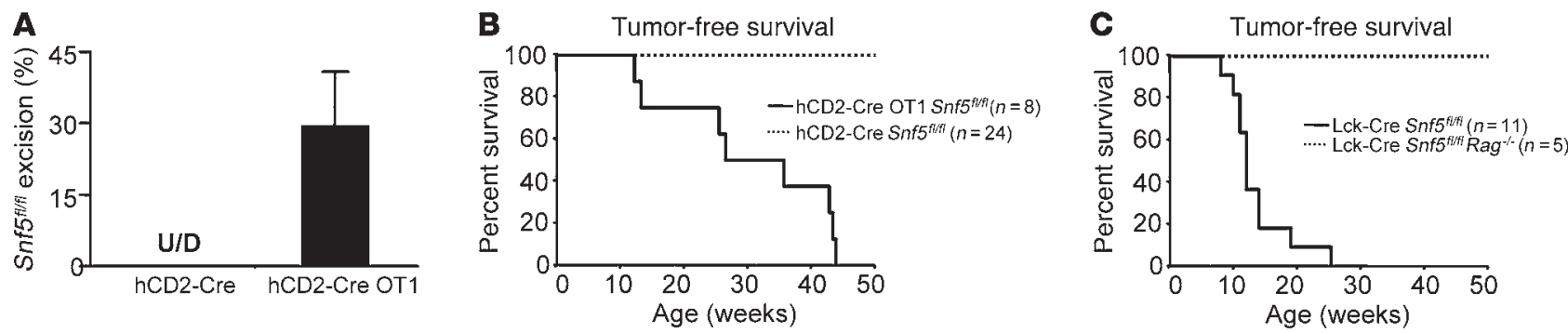

Figure 6

Oncogenesis caused by Snf5 loss is TCR signaling dependent. (A) CD3+CD8+ T cells were sorted from the spleens of hCD2-Cre Snf5fl/fl mice $(n=6)$ or hCD2-Cre OT-1 Snff fl/fl mice $(n=4)$, and deletion of the Snf5 allele was quantified by quantitative real-time PCR. The deleted allele was undetectable in $\mathrm{CD}^{+} \mathrm{CD} 8^{+} \mathrm{T}$ cells from the hCD2-Cre Snf5 fl/fl mice. (B) Tumor-free survival curve of hCD2-Cre Snf5 $5^{f / f l}$ mice $(n=24)$ and hCD2-Cre OT-1+ Snf5 fl/fl $(n=8)$ mice. (C) Tumor-free survival curve of Lck-Cre Snf5 fl/fl mice $(n=11)$ and Lck-Cre Snf5 $5^{f / f l}$ Rag2 $2^{-/-}(n=5)$ mice.

grow well in mice (46). Here, we have used a series of deleter strains to generate genetically engineered murine models of spontaneously arising PTCLs.

Snf5 is recurrently mutated in human cancers and has potent tumor suppressor activity in mouse models, but the underlying mechanism has been largely unclear. We and others have identified epigenetic antagonism between Polycomb and Swi/Snf complexes, and we recently reported an essential role for imbalance of this epigenetic relationship in transformation caused by Snf5 loss $(35,47$, 48). In addition, we found an important role for aberrant activation of the Hedgehog-Gli pathway, a mediator of stem cell identity, caused by Snf5 loss (49). Here, we build on these findings by showing that Snf5 loss in T cells leads to activation of both Myc signatures and core stem cell-associated programs. Therefore, the effects of Snf5 inactivation in T cell lymphomas correlate with those in primary fibroblasts, suggesting a theme of epigenetically mediated activation of proliferation and stem cell programs after Snf5 loss.

Additionally, a major finding is that mature $\mathrm{T}$ cells that display a CD8 ${ }^{+} \mathrm{CD} 44^{\text {hi }} \mathrm{CD} 122^{\text {lo }}$ phenotype consistent with that of a subset of memory $\mathrm{T}$ cells are uniquely responsive to the consequences of Snf5 loss, thus providing insight into the initiation and maintenance of these lymphomas. Given that (a) the lymphomas arise exclusively in the periphery, in which they involve the spleen, liver, and lymph nodes but never thymus; (b) that Snf5 protein is not fully lost until cells reach the periphery; and (c) that the propagating cells express high levels of CD44, which is expressed at low levels in $\mathrm{CD}^{+}$thymocytes but at high levels in peripheral memory cells, the tumor-originating $\mathrm{T}$ cell is likely mature and peripheral in nature. However, we cannot totally exclude initiation from a late thymic $\mathrm{T}$ cell. Memory $\mathrm{CD}^{+} \mathrm{T}$ cells are a unique population of differentiated cells that share several properties with stem cells, including longevity and continuous and slow self-renewal, combined with the capacity for extensive and robust proliferation (12, 50-53). Indeed, bioinformatic analysis has revealed that HSCs and memory $\mathrm{CD}^{+} \mathrm{T}$ cells share a similar transcriptional program of activation (54) and self renewal (23), perhaps reflecting a predicted evolutionary co-opting of cooperative gene sets (55). Collectively, our findings suggest that unlike mouse embryonic fibroblasts (MEFs) or naive T cells, memory $\mathrm{T}$ cells are intrinsically responsive to activation of these stem cell-associated and Myc programs, thus rendering them susceptible to transformation.

The $\mathrm{CD} 8{ }^{+} \mathrm{CD} 44^{\text {hi }} \mathrm{CD} 122^{\text {lo }}$ subset delineated in this report differs in several ways from canonical memory $\mathrm{T}$ cells. This cellular subset displays a high background rate of proliferation, expresses surface markers characteristic of recently activated $\mathrm{T}$ cells, preferentially homes to the spleen (the principal location of Snf5-deficient lymphomas), and has features of chronically activated $\mathrm{T}$ cells secondary to indolent infection (28). As chronic infections are a well-recognized risk factor for development of several types of lymphoma, this opens the mechanistic possibility that chronic stimulation of memory cells results in enhanced susceptibility to oncogenic transformation. $\mathrm{CD}^{+} \mathrm{CD} 44^{\text {hi }} \mathrm{CD} 122^{\text {lo }}$ memory cells, like Snf5-deficient CD8 ${ }^{+}$lymphomas, depend on TCR engagement and thus survive poorly in MHC class I-deficient mice (28). Collectively, these properties and the high basal rate of proliferation may make this memory subset particularly susceptible to transformation. Lastly, while the precise molecular function of CD44 is poorly understood, this surface protein marks cancer stem cells in several types of solid tumors and is repressed by Snf5 $(2,29,47)$. Consequently, it is possible that the high levels of CD44 expressed by CD8 memory cells and lymphoma-initiating cells described here may also contribute to cellular transformation.

TCR signaling and lymphomagenesis. It has been shown that many nonlymphoid cancers, such as prostate and breast cancers, continue to depend on physiologic lineage-specific signals, such as androgen and estrogen receptor signaling (56-58). However, the role of immune receptor signaling in lymphoid tumors has been unclear. Intriguingly, recent data suggest that a chronic immune response to microbial or possibly self antigens may underlie the formation of noncancerous, age-related expansions of CD8 memory cells, suggesting that TCR signaling can contribute to clonal disorders (59). With respect to PTCLs, genome-wide expression analyses have also revealed that PTCL cells are enriched for a gene expression signature of activated T cells $(45,60)$. Moreover, it has recently been shown that the fusion of ITK-SYK caused by the $t(5 ; 9)$ (q33;q22) chromosomal translocation present in $17 \%$ of PTCLs can mimic a TCR signal and can drive tumorigenesis in a conditional mouse model (61). However, any role for TCR engagement in malignancy has remained speculative. Collectively, our data demonstrate that, despite being monoclonal and transplantable, TCR signaling is essential for proliferation of these mature T cell lymphomas: low-affinity TCRMHC interactions that promote survival of naive $\mathrm{CD}^{+} \mathrm{T}$ cells and the $\mathrm{CD} 44^{\text {hi }} \mathrm{CD} 122^{\text {lo }}$ subset of memory $\mathrm{CD}^{+}$cells are sufficient to drive lymphoma expansion. While expression of a transgenic TCR is essential for lymphoma development in CD2-Cre mice, we cannot exclude the possibility that TCR signaling does not specifically drive initial transformation but rather facilitates maturation and is subsequently required to maintain proliferation of the lymphoma cells after transformation. 
A

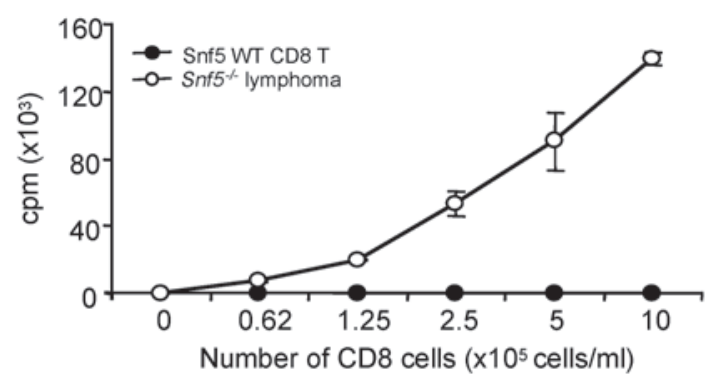

C

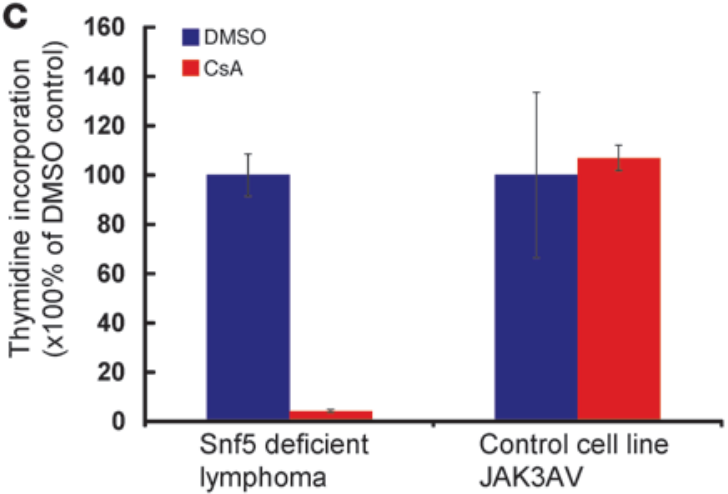

$\mathbf{E}$

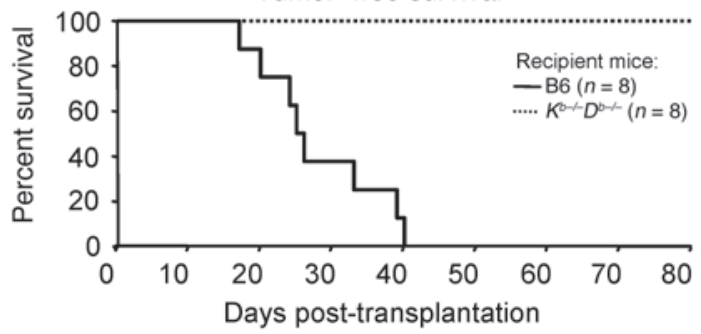

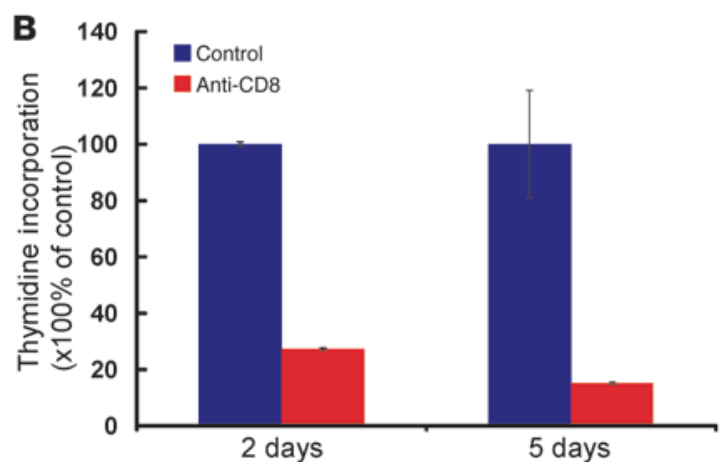

D

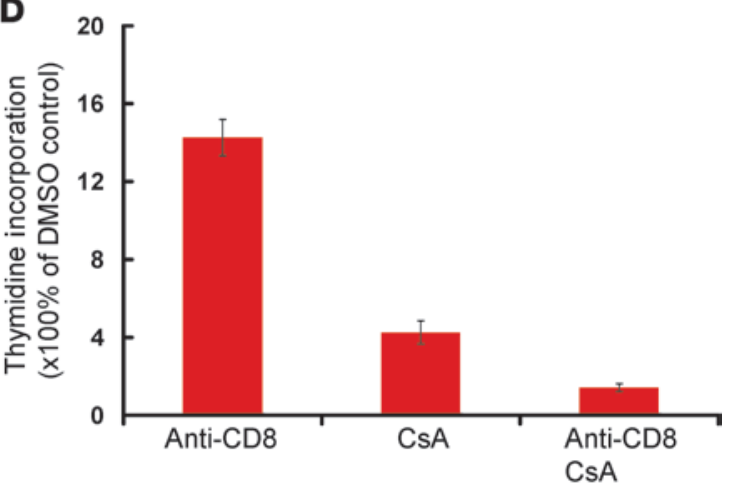

Figure 7

Blockade of TCR signaling leads to growth arrest of Snf5-deficient lymphoma cells. (A) CD8-enriched cells from Lck-Cre Snf5+/+ mice (indicated as Snf5 WT CD8 T) or tumor-bearing Lck-Cre Snf5 fl/tI mice (indicated as Snf5-/-lymphoma) were stimulated for 60 hours in vitro in increasing numbers in the presence of syngeneic APCs. Proliferation was measured by $3 \mathrm{H}$-Thymidine incorporation. (B) The Snf5-deficient lymphoma cell line was cultured for 2 days or 5 days in vitro in the presence of $1 \mu \mathrm{g} / \mathrm{ml}$ anti-CD $8 \alpha$ or isotype control. Proliferation was measured by $3 \mathrm{H}-\mathrm{Thymine}$ incorporation. (C) The Snf5-deficient lymphoma cell line or a control cell line was cultured for 5 days in vitro in the presence or absence of $5 \mu \mathrm{g} / \mathrm{ml}$ CsA. Proliferation was measured by $3 \mathrm{H}$-Thymine incorporation. (D) The Snf5-- lymphoma cell line was cultured for 5 days in vitro in the presence of $1 \mu \mathrm{g} / \mathrm{ml}$ anti-CD $8 \alpha$ and $5 \mu \mathrm{g} / \mathrm{ml}$ CsA. Proliferation was measured by $3 \mathrm{H}$-Thymine incorporation. (E) Tumor-free survival of sublethally irradiated $\mathrm{B} 6$ or $\mathrm{MHC}$ class I-deficient $K^{b-/-} D^{b-1-}$ mice after intravenous transfer of $106 \mathrm{CD} 8$-enriched cells from tumor-bearing Lck-Cre Snf5 fl/tI mice.

The relevance of this model to human lymphomas is enhanced by our finding that $40 \%$ of human PTCLs express SNF5 at low or undetectable levels. It is noteworthy that while inactivating mutations of SNF5 drive cancer formation, hypofunction is also associated with cancer. For instance, inactivating mutations occur in rhabdoid tumors, while less severe mutations are found in familial Schwannomatosis $(13,15,62,63)$. Similarly, reduced expression of SNF5 is associated with high-risk disease in acute lymphoblastic leukemia (64). Additionally, 50\% of $\mathrm{T}$ cell prolymphocytic leukemias carry deletions at $22 \mathrm{q} 11$, the region in which SNF5 is encoded (19), and a possible role for haploinsufficiency of SNF5 in the genesis of these mature T cell cancers has been raised (20). Similarly, Brg1-haploinsufficient mice are predisposed to breast cancers in which the remaining WT allele is always retained. Most recently, the ARID1A subunit of the SWI/SNF complex has been found specifically mutated in $50 \%$ of ovarian clear cell carcinomas $(65,66)$. Notably, while many of these cancers have biallelic inactivating mutations and complete loss of the ARID1A protein, a substantial percentage harbor only heterozygous mutations and express some ARID1A protein, suggesting a haploinsufficient mechanism (66). Collectively, it is clear that a reduction in the levels of expression of SWI/SNF subunits can drive cancer formation, and, consequently, the low levels of Snf5 that we've identified in human PTCLs suggest that SNF5 may well act as an important tumor suppressor in for these cancers. 


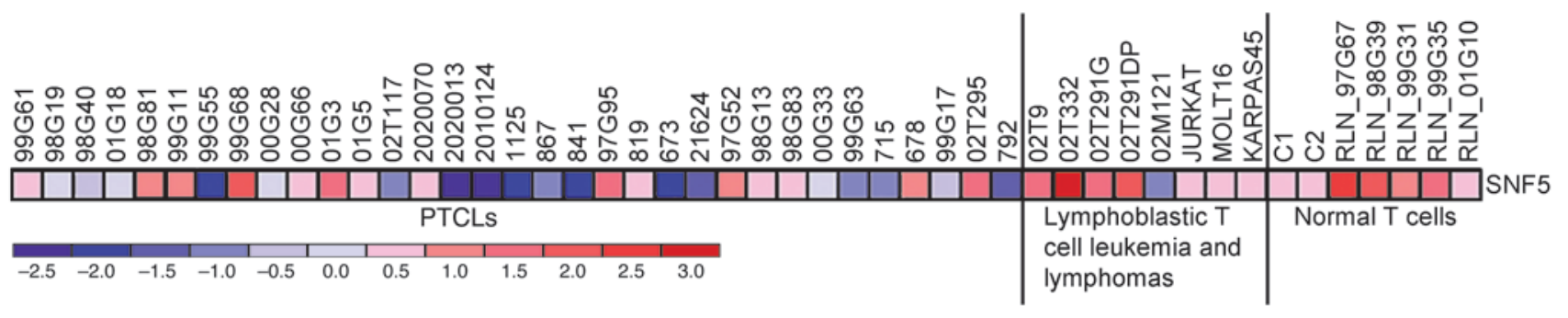

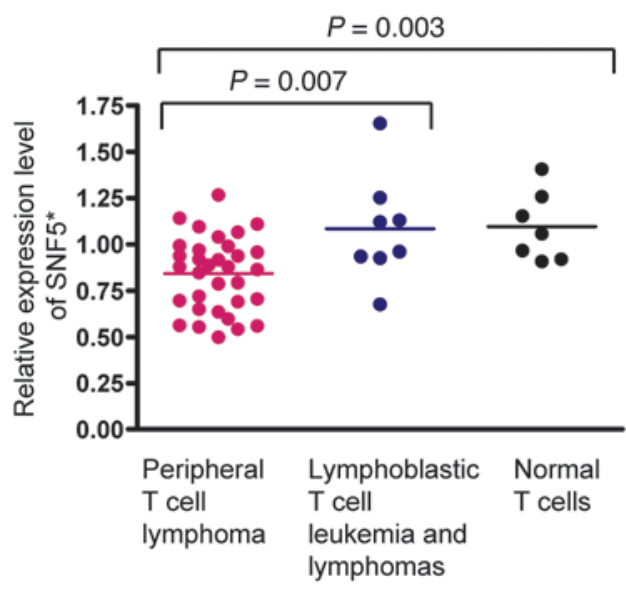

Blockade of TCR signaling may be therapeutically useful in peripherallymphomas. Mature PTCLs are diverse morphologically but similar in that the majority express TCR and carry an extremely poor prognosis $(44,45,67)$. Treatment options for these cancers are limited and tend to be ineffective. The finding that murine Snf5-deficient lymphomas depend on TCR-MHC interactions led us to ask whether suppression of TCR signaling may be therapeutically beneficial, akin to estrogen or androgen blockade in breast and prostate cancers. Our results open the possibility that a similar approach may be effective for mature lymphomas. We have shown here that blockade of TCR-MHC interaction effectively reduces proliferation of established Snf5-deficient lymphoma cells. One of the downstream events after TCR engagement is activation of calcineurin, which leads to NFAT nuclear translocation/activation and upregulation of apoptosis resistance genes $(38,39)$. Inhibition of the NFAT pathway by CsA can induce apoptosis, tumor clearance, and substantially prolonged mouse survival (40). Since the effects of CsA on Snf5deficient lymphomas are enhanced in a synergistic fashion by treatment with anti-CD8, administration of CsA in combination with upstream blockade of the TCR pathway may halt propagation of at least some PTCLs and is worthy of further investigation.

\section{Methods}

\section{Snf5 excision PCR}

Total genomic DNA extracted from sorted T cells was analyzed for snf5 excision by PCR. Primers used for the amplification of both the WT and nonrecombined floxed allele are Snf5-1, CACCATGCCCCCACCTCCCCTACA, and Snf5-2, CAGGAAAATGGATGCAACTAAGAT. Primers used for the amplification of recombined floxed Snf5 allele are Snf5-3, AGACTGGCCTGATTTGTTTAATATG, and Snf5-4, TACACGATGAGATCTTGTCTCAAAA. PCR products were detected by either ethidium bromide staining of agarose gels or quantitative realtime PCR using iQ SYBR Green Supermix (Bio-Rad).

\section{Figure 8}

SNF5 is expressed at low levels in human PTCLs. Heat map analysis of SNF5 in 33 PTCLs, 8 immature lymphoblastic T cell leukemia/lymphomas, and normal T cells isolated from either peripheral blood (C1 and C2) or reactive lymph nodes. The average expression of SNF5 across all the PTCLs is significantly lower than that in either normal cells $(P<0.003)$ or immature lymphoblastic $T$ cell leukemia/lymphomas $(P<0.007)$. Horizontal bars indicate the mean.

\section{Mouse models and cell lines}

Genotyping was done by PCR analysis of tail DNA as previously reported $(22,27,68)$. The Snf5-deficient lymphoma cell line was generated by 3 sequential adoptive transfers of CD8-enriched splenocytes originally from Lck-Cre $\mathrm{GFP}^{+} \operatorname{Snf} 5^{f / / f l}$ tumor-bearing mice into irradiated C57BL/6 host animals, followed by culture of the cells in DMEM supplemented with $10 \%$ FCS. JAK3AV lymphoma cells were provided by the laboratory of Gary Gilliland (Harvard Medical School). Lck-Cre and CD4-Cre mice were obtained from Christopher Wilson (University of Washington, Seattle, Washington, USA). Mice were housed under pathogen-free conditions. Animal handling and experimental procedures were approved by and were in accordance with institutional requirements for animal care and use of The Harvard Center for Comparative Medicine (HCCM), Boston, Massachusetts, USA.

\section{Cell preparations and flow cytometry}

Data were collected using a FACSCalibur cytometer (Becton Dickinson) and analyzed with FlowJo software (Tree Star) or isolated by fluorescenceactivated cell sorting on a BD FACSAria sorter (Becton Dickinson). Fluorochrome-conjugated mAbs against CD3ع (145-2C11), CD4 (RM4-5), CD8 $\alpha$ (53-6.7), CD25 (7D4), CD122 (TM 31 ), and CD44 (IM7) were purchased from BD Pharmingen. The Mouse V $\beta$ TCR Screening Panel was purchased from BD Pharmingen.

\section{Tumor transplantation}

Lymphoma cells were purified by negative selection using the mouse CD8 T lymphocyte enrichment set from BD Pharmingen according to manufacturer's protocol (catalog no. 558471) and then were transferred intravenously into sublethally irradiated (4 Gy) B6 (Charles River Laboratories), $\mathrm{Kb}^{-/-} \mathrm{Db} b^{-/-}$(C57BL/6-H-2Kbtm1H-2Dbtm1, NIAID Exchange Program, NIH:4215; ref. 41), or $I l 15^{-/-}$mice (Taconic).

\section{In vitro proliferation assay}

Enriched CD8 T cells from tumor-bearing mice or littermate controls were cultured at varying concentrations with $2.5 \times 10^{6}$ irradiated $\mathrm{T}$ cell-depleted 
splenocytes and either $1 \mu \mathrm{g} / \mathrm{ml}$ purified anti-CD8 $\alpha$ (clone 2.43, National Cell Culture Center, Minneapolis, Minnesota) or $1 \mu \mathrm{g} / \mathrm{ml}$ purified isotype control (BD Pharmingen) or at the concentration of $4 \times 10^{5}$ cells per well in the presence of increasing concentrations of recombinant IL-15 (PeproTech). The Snf5-deficient lymphoma cell line was cultured in the presence of $1 \mu \mathrm{g} / \mathrm{ml}$ purified anti-CD8 $\alpha$ or $1 \mu \mathrm{g} / \mathrm{ml}$ purified isotype control, with or without $5 \mathrm{mg} / \mathrm{ml} \mathrm{CsA}$ (Sigma-Aldrich). Proliferation was measured by ${ }^{3} \mathrm{H}$-Thymidine incorporation $(2 \mu \mathrm{Ci} /$ well).

\section{Antibodies for Western blots}

Anti-Snf5 antibody (catalog no. 612110) was purchased from BD Biosciences, and anti-actin antibody (mAbcam 8226) was purchased from Abcam. NFAT1 antibody is a gift from Anjana Rao (Harvard Medical School). Myc antibody was purchased from Cell Signaling Technology.

\section{RNA purification and RT-PCR}

Total RNA was extracted using TRIzol Reagent (Invitrogen) and reverse transcribed by the Reverse Transcription System (Promega). Gene expression was normalized to RPS8. Error bars in RNA analysis represent standard deviations of mean expression or fold changes based on at least 3 independent RNA isolations or are indicated in figure legends. Primers used for real-time PCR reactions are BclxL-F, CCTTCAGGCCTCTCTCTCCT, and BclxL-R, CCAGCAGCTCCTCACACATA.

\section{Immunostaining}

For immunohistochemistry, mouse and human tissues (thymus, spleen, and lymph nodes) were fixed in $10 \%$ formaldehyde, processed, and paraffin embedded; 4- $\mu \mathrm{m}$ sections underwent antigen retrieval (EDTA, $\mathrm{pH} 8$, Invitrogen, catalog no. 00-5500) in a steam pressure cooker (Decloaking Chamber, BioCare Medical) and were stained with anti-CD3 (rabbit polyclonal antibody, Dako, catalog no. A0452; 1:250 [for human tissues]; 1:1,000 [for mouse tissues]) or with anti-SNF5 (BAF47) (mouse monoclonal antibody, BD Transduction Laboratories, catalog no. 612111; lot no. 04991 [250 $\mu \mathrm{g} / \mathrm{ml}] ; 1: 100$ [for human tissues]; 1:200 [for mouse tissues]). In addition, for mouse tissues, a Mouse-on-Mouse blocking reagent was used (Vector Laboratories, catalog no. MKB-2213). Diaminobenzidine signals were achieved according to manufacturer's protocol (EnVision Kit, Dako, catalog no. K4007 and K4011). For double staining on human tissues, anti-BAF47 antibody was used at 1:100 (diaminobenzidine signal), and anti-CD3 was used at 1:250 with the Vulcan Fast Red Chromogen Kit 2 (Biocare Medical, catalog no. FR805H). All human samples used were deidentified, discarded tissues.

\section{Microarray bybridization and data processing}

RNA purification. Total RNA was extracted using TRIzol Reagent (Invitrogen) and reverse transcribed by the Reverse Transcription System (Promega). The Raw Microarray data were deposited into the GEO data repository (accession no. GSE23659 [ref. 35] and GSE29732; http://www. ncbi.nlm.nih.gov/geo/).

Preprocessing. We processed the raw gene expression values with the robust multi-array analysis algorithm (69) using GenePattern software (70).

Combining and clustering samples across microarray platforms. As data were derived from different Affymetrix platforms (Mouse Genome 430A 2.0 and $\mathrm{U} 74 \mathrm{v} 2$; see http://www.affymetrix.com for details), we translated the expression measures from microarray-specific probe sets to platformindependent representative measures of gene expression. We mapped the
Affymetrix probe set tags to UniGene (71) IDs and discarded UniGene IDs that were not common to both microarray platforms. With a list of common UniGene IDs, we translated each data set's expression values to scaled expression values that were consistent across the data sets, thereby making the distributions of gene expression values as similar as possible. This scaling lessened the experimental and computational artifacts among data sets. We did this translation with quantile scaling using the following steps. We calculated the mean expression value of each UniGene across all samples and stored these mean values in a database and sorted their ranks in a table. Then, for each sample, for each UniGene, we calculated each UniGene's rank, matched that sample-specific rank to the same rank in the database, and replaced that UniGene's expression value in the current sample with the corresponding expression value from the database.

Clustering and classifying. To calculate the similarity among the samples, we performed k-nearest $(\mathrm{KNN})$ classifier (70), with $k=3$ to classify the $\mathrm{CD} 44^{\mathrm{hi}}$ and $\mathrm{CD} 44^{\mathrm{lo}}$ samples by using a previously published database of memory and naive cells as reference samples (23).

GSEA. We created gene sets of the most differentially expressed genes (with a $P$ value of less than 0.01 and fold change greater than 2 ) in either direction between the memory and the naive cells (23). Then we performed GSEA (30) to measure enrichment of these gene sets in the $\mathrm{CD} 44^{\text {hi }}$ and $\mathrm{CD} 44^{\text {lo }}$ samples. For all GSEA runs, we used the signal-tonoise ratio to rank order the genes based on their ability to distinguish the reference classes, and we used 1,000 permutations for permutation testing for statistical significance.

\section{Statistics}

A 2-tailed $t$ test was used to determine significance of difference throughout this study. Statistics were computed by GraphPad Prism 4. Error bars in all the figures represent SEM. A value of $P<0.05$ was considered statistically significant.

\section{Acknowledgments}

The authors thank Christopher Wilson for supplying the Lck-Cre and CD4-Cre strains, Anjana Rao for supplying the NFAT1 antibody, and Diana Alvarez Arias and Jonghwan Kim for technical assistance. The authors are also grateful to John Luckey, Nicholas Haining, and members of Cantor and Roberts laboratories for helpful discussion. C.W.M. Roberts was supported in part by the Garrett B. Smith Foundation, PHS awards R01CA113794 and U01-1156106, and a Stand Up to Cancer Innovative Research Grant from the American Association of Cancer Research. H. Cantor was supported in part by a gift from the Gherrin-Gelli Trust. C.G. Sansam was supported by PHS awards F32CA123776 and Hope Street Kids foundation. B.G. Wilson was supported by the Ruth L. Kirschstein National Research Service Award Fellowship 1 F32 CA130312-01A1 from the National Cancer Institute

Received for publication March 28, 2011, and accepted in revised form August 3, 2011.

Address correspondence to: Charles W.M. Roberts, Dana-Farber Cancer Institute, Mayer 657, 44 Binney Street, Boston, Massachusetts 02115, USA. Phone: 617.632.6497; Fax: 617.582.8096; E-mail: charles_roberts@dfci.harvard.edu.
1. Krivtsov AV, et al. Transformation from committed progenitor to leukaemia stem cell initiated by MLL-AF9. Nature. 2006;442(7104):818-822.

2. Park CY, Tseng D, Weissman IL. Cancer stem celldirected therapies: recent data from the laboratory and clinic. Mol Ther. 2009;17(2):219-230.

3. Wong DJ, Liu H, Ridky TW, Cassarino D, Segal E, Chang HY. Module map of stem cell genes guides creation of epithelial cancer stem cells. Cell Stem Cell. 2008;2(4):333-344
4. Ben-Porath I, et al. An embryonic stem cell-like gene expression signature in poorly differentiated aggressive human tumors. Nat Genet. 2008; 40(5):499-507.

5. Hope KJ, Jin L, Dick JE. Acute myeloid leukemia 
originates from a hierarchy of leukemic stem cell classes that differ in self-renewal capacity. Nat Immunol. 2004;5(7):738-743.

6. O’Brien CA, Pollett A, Gallinger S, Dick JE. A human colon cancer cell capable of initiating tumour growth in immunodeficient mice. Nature. 2007;445(7123):106-110.

7. Singh SK, et al. Identification of human brain tumour initiating cells. Nature. 2004;432(7015):396-401.

8. Bachoo RM, et al. Epidermal growth factor receptor and Ink4a/Arf: convergent mechanisms governing terminal differentiation and transformation along the neural stem cell to astrocyte axis. Cancer Cell. 2002;1(3):269-277.

9. Somervaille TC, Cleary ML. Identification and characterization of leukemia stem cells in murine MLL-AF9 acute myeloid leukemia. Cancer Cell. 2006;10(4):257-268.

10. Roberts CW, Orkin SH. The SWI/SNF complexchromatin and cancer. Nature Rev Cancer. 2004; 4(2):133-142.

11. Singhal N, et al. Chromatin-remodeling components of the BAF complex facilitate reprogramming. Cell. 2010;141(6):943-955.

12. Ho L, et al. An embryonic stem cell chromatin remodeling complex, esBAF, is essential for embryonic stem cell self-renewal and pluripotency. Proc Natl Acad Sci U S A. 2009;106(13):5181-5186.

13. Biegel JA, Zhou JY, Rorke LB, Stenstrom C, Wainwright LM, Fogelgren B. Germ-line and acquired mutations of INI1 in atypical teratoid and rhabdoid tumors. Cancer Res. 1999;59(1):74-79.

14. Taylor MD, Gokgoz N, Andrulis IL, Mainprize TG, Drake JM, Rutka JT. Familial posterior fossa brain tumors of infancy secondary to germline mutation of the hSNF5 gene. Am J Hum Genet. 2000;66(4):1403-1406

15. Versteege I, et al. Truncating mutations of hSNF5/ INI1 in aggressive paediatric cancer. Nature. 1998; 394(6689):203-206.

16. Kreiger PA, et al. Loss of INI1 expression defines a unique subset of pediatric undifferentiated soft tissue sarcomas. Mod Pathol. 2009;22(1):142-150.

17. Xia W, et al. BAF180 is a critical regulator of $\mathrm{p} 21$ induction and a tumor suppressor mutated in breast cancer. Cancer Res. 2008;68(6):1667-1674.

18. Varela I, et al. Exome sequencing identifies frequent mutation of the SWI/SNF complex gene PBRM1 in renal carcinoma. Nature. 2011;469(7331):539-542.

19. Soulier J, et al. A complex pattern of recurrent chromosomal losses and gains in T-cell prolymphocytic leukemia. Genes Chromosomes Cancer. 2001; 31(3):248-254

20. Bug S, et al. Recurrent loss, but lack of mutations, of the SMARCB1 tumor suppressor gene in T-cell prolymphocytic leukemia with TCL1A-TCRAD juxtaposition. Cancer Genet Cytogenet. 2009;192(1):44-47.

21. Wang X, et al. Oncogenesis caused by loss of the SNF5 tumor suppressor is dependent on activity of BRG1, the ATPase of the SWI/SNF chromatin remodeling complex. Cancer Res. 2009;69(20):8094-8101.

22. Roberts CW, Leroux MM, Fleming MD, Orkin SH. Highly penetrant, rapid tumorigenesis through conditional inversion of the tumor suppressor gene Snf5. Cancer Cell. 2002;2(5):415-425.

23. Luckey CJ, Bhattacharya D, Goldrath AW, Weissman IL, Benoist C, Mathis D. Memory T and memory B cells share a transcriptional program of selfrenewal with long-term hematopoietic stem cells. Proc Natl Acad Sci USA. 2006;103(9):3304-3309.

24. Bonnet D, Dick JE. Human acute myeloid leukemia is organized as a hierarchy that originates from a primitive hematopoietic cell. Nat Med. 1997; 3(7):730-737.

25. Dick JE. Stem cell concepts renew cancer research. Blood. 2008;112(13):4793-4807.

26. Weissman IL, McGrath MS. Retrovirus lymphomagenesis: relationship of normal immune receptors to malignant cell proliferation. Curr Top Microbiol Immunol. 1982;98:103-112.

27. Lee PP, et al. A critical role for Dnmt1 and DNA methylation in T cell development, function, and survival. Immunity. 2001;15(5):763-774.

28. Boyman O, Cho JH, Tan JT, Surh CD, Sprent J. A major histocompatibility complex class I-dependent subset of memory phenotype CD8+ cells. J Exp Med. 2006;203(7):1817-1825.

29. Boman BM, Wicha MS. Cancer stem cells: a step toward the cure. JClin Oncol. 2008;26(17):2795-2799.

30. Subramanian A, et al. Gene set enrichment analysis: a knowledge-based approach for interpreting genome-wide expression profiles. Proc Natl Acad Sci US A. 2005;102(43):15545-15550.

31. Swanson BJ, Murakami M, Mitchell TC, Kappler J, Marrack P. RANTES production by memory phenotype $T$ cells is controlled by a posttranscriptional, TCR-dependent process. Immunity. 2002; 17(5):605-615

32. Walzer T, Marcais A, Saltel F, Bella C, Jurdic P, Marvel J. Cutting edge: immediate RANTES secretion by resting memory CD8 $\mathrm{T}$ cells following antigenic stimulation. J Immunol. 2003;170(4):1615-1619.

33. Chi TH, et al. Sequential roles of Brg, the ATPase subunit of BAF chromatin remodeling complexes, in thymocyte development. Immunity. 2003; 19(2):169-182.

34. Chi TH, et al. Reciprocal regulation of CD4/CD8 expression by SWI/SNF-like BAF complexes. Nature. 2002;418(6894):195-199.

35. Wilson BG, et al. Epigenetic antagonism between polycomb and SWI/SNF complexes during oncogenic transformation. Cancer Cell. 2010;18(4):316-328.

36. Kim J, et al. A Myc network accounts for similarities between embryonic stem and cancer cell transcription programs. Cell. 2010;143(2):313-324.

37. Isakoff MS, et al. Inactivation of the Snf5 tumor suppressor stimulates cell cycle progression and cooperates with p53 loss in oncogenic transformation. Proc Natl Acad Sci USA. 2005;102(49):17745-17750.

38. Macian F. NFAT proteins: key regulators of T-cell development and function. Nat Rev Immunol. 2005;5(6):472-484.

39. Rao A, Luo C, Hogan PG. Transcription factors of the NFAT family: regulation and function. Annu Rev Immunol. 1997;15:707-747.

40. Medyouf $\mathrm{H}$, et al. Targeting calcineurin activation as a therapeutic strategy for T-cell acute lymphoblastic leukemia. Nat Med. 2007;13(6):736-741.

41. Perarnau B, et al. Single H2Kb, H2Db and double $\mathrm{H} 2 \mathrm{KbDb}$ knockout mice: peripheral CD8+ T cell repertoire and anti-lymphocytic choriomeningitis virus cytolytic responses. Eur J Immunol. 1999; 29(4):1243-1252.

42. Martinez-Delgado B, et al. Expression profiling of T-cell lymphomas differentiates peripheral and lymphoblastic lymphomas and defines survival related genes. Clin Cancer Res. 2004;10(15):4971-4982.

43. Kuppers R, Klein U, Hansmann ML, Rajewsky K Cellular origin of human B-cell lymphomas. NEngl JMed. 1999;341(20):1520-1529.

44. Rudiger T, Geissinger E, Muller-Hermelink HK 'Normal counterparts' of nodal peripheral T-cell lymphoma. Hematol Oncol. 2006;24(4):175-180.

45. Savage KJ. Peripheral T-cell lymphomas. Blood Rev. 2007;21(4):201-216.

46. Waller EK, et al. Growth of primary T-cell nonHodgkin's lymphomata in SCID-hu mice: requirement for a human lymphoid microenvironment. Blood. 1991;78(10):2650-2665.

47. Oruetxebarria I, et al. P16INK4a is required for hSNF5 chromatin remodeler-induced cellular senescence in malignant rhabdoid tumor cells. J Biol Chem. 2004;279(5):3807-3816.

48. Kia SK, Gorski MM, Giannakopoulos S, Verrijzer CP. SWI/SNF mediates polycomb eviction and epigenetic reprogramming of the INK4b-ARF-INK4a locus. Mol Cell Biol. 2008;28(10):3457-3464.

49. Jagani $Z$, et al. Loss of the tumor suppressor Snf5 leads to aberrant activation of the Hedgehog-Gli pathway. Nat Med. 2010;16(12):1429-1433.

50. Masopust D, Vezys V, Wherry EJ, Ahmed R. A brief history of CD8 T cells. Eur J Immunol. 2007; 37 suppl 1:S103-S110.

51. Prlic M, Williams MA, Bevan MJ. Requirements for CD8 T-cell priming, memory generation and maintenance. Curr Opin Immunol. 2007;19(3):315-319.

52. Lanzavecchia A, Sallusto F. Understanding the generation and function of memory $\mathrm{T}$ cell subsets. Curr Opin Immunol. 2005;17(3):326-332.

53. Surh CD, Sprent J. Homeostasis of naive and memory T cells. Immunity. 2008;29(6):848-862.

54. Chambers SM, et al. Hematopoietic fingerprints: an expression database of stem cells and their progeny. Cell Stem Cell. 2007;1(5):578-591.

55. Rothenberg EV, Pant R. Origins of lymphocyte developmental programs: transcription factor evidence. Semin Immunol. 2004;16(4):227-238.

56. Biganzoli L, Licitra S, Claudino W, Pestrin M, Leo AD. Clinical decision making in breast cancer: TAM and aromatase inhibitors for older patients -- a jungle? Eur J Cancer. 2007;43(15):2270-2278.

57. Boccon-Gibod L, Hammerer P, Madersbacher S, Mottet N, Prayer-Galetti T, Tunn U. The role of intermittent androgen deprivation in prostate cancer. BJU Int. 2007; 100(4):738-743.

58. Utsumi T, Kobayashi N, Hanada H. Recent perspectives of endocrine therapy for breast cancer. Breast Cancer. 2007;14(2):194-199.

59. Clambey ET, White J, Kappler JW, Marrack P. Identification of two major types of age-associated CD8 clonal expansions with highly divergent properties. Proc Natl Acad Sci U S A. 2008; 105(35):12997-13002.

60. Piccaluga PP, et al. Gene expression analysis of peripheral $\mathrm{T}$ cell lymphoma, unspecified, reveals distinct profiles and new potential therapeutic targets. J Clin Invest. 2007;117(3):823-834.

61. Pechloff K, et al. The fusion kinase ITK-SYK mimics a $\mathrm{T}$ cell receptor signal and drives oncogenesis in conditional mouse models of peripheral $\mathrm{T}$ cell lymphoma. J Exp Med. 2010;207(5):1031-1044.

62. Hulsebos TJ, Plomp AS, Wolterman RA, RobanusMaandag EC, Baas F, Wesseling P. Germline mutation of INI1/SMARCB1 in familial schwannomatosis. Am J Hum Genet. 2007;80(4):805-810.

63. Boyd C, Smith MJ, Kluwe L, Balogh A, Maccollin $\mathrm{M}$, Plotkin SR. Alterations in the SMARCB1 (INI1) tumor suppressor gene in familial schwannomatosis. Clin Genet. 2008;74(4):358-366

64. Holleman A, et al. Gene-expression patterns in drug-resistant acute lymphoblastic leukemia cells and response to treatment. $N$ Engl J Med. 2004; 351(6):533-542.

65 . Jones $\mathrm{S}$, et al. Frequent mutations of chromatin remodeling gene ARID1A in ovarian clear cell carcinoma. Science. 2010;330(6001):228-231.

66. Wiegand KC, et al. ARID1A mutations in endometriosis-associated ovarian carcinomas. $N$ Engl J Med 2010;363(16):1532-1543.

67. de Leval L, Bisig B, Thielen C, Boniver J, Gaulard P. Molecular classification of T-cell lymphomas. Crit Rev Oncol Hematol. 2009;72(2):125-143.

68 . de Boer J, et al. Transgenic mice with hematopoietic and lymphoid specific expression of Cre. Eur J Immunol. 2003;33(2):314-325.

69. Irizarry RA, et al. Exploration, normalization, and summaries of high density oligonucleotide array probe level data. Biostatistics. 2003;4(2):249-264.

70. Reich M, Liefeld T, Gould J, Lerner J, Tamayo P, Mesirov JP. GenePattern 2.0. Nat Genet. 2006;38(5):500-501.

71. Wheeler DL, et al. Database resources of the National Center for Biotechnology. Nucleic Acids Res. 2003;31(1):28-33. 